\title{
Saci_1816: A Trehalase that Catalyzes Trehalose Degradation in the Thermoacidophilic Crenarchaeon Sulfolobus acidocaldarius
}

\author{
Junho Lee ${ }^{1}$, Areum Lee ${ }^{1}$, Keumok Moon ${ }^{1}$, Kyoung-Hwa Choi ${ }^{1}$, and Jaeho Cha ${ }^{1,2 *}$ \\ ${ }^{1}$ Department of Microbiology, College of Natural Sciences, Pusan National University, Busan 46241, Republic of Korea \\ ${ }^{2}$ Microbiological Resource Research Institute, Pusan National University, Busan 46241, Republic of Korea
}

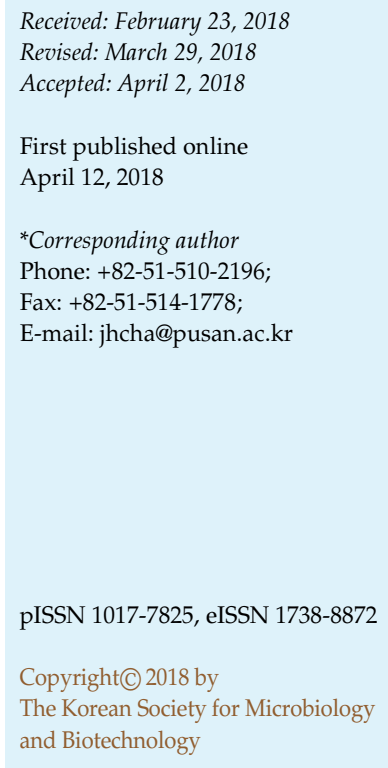

Previously, a cytosolic trehalase (TreH) from the hyperthermophilic archaeon Sulfolobus acidocaldarius was reported; however, the gene responsible for the trehalase activity was not identified. Two genes, saci_1816 and saci_1250, that encode the glycoside hydrolase family 15 type glucoamylase-like proteins in S. acidocaldarius were targeted and expressed in Escherichia coli, and their abilities to hydrolyze trehalose were examined. Recombinant Saci_1816 hydrolyzed trehalose exclusively without any help from a cofactor. The mass spectrometric analysis of partially purified native TreH also confirmed that Saci_1816 was involved in proteins exhibiting trehalase activity. Optimal trehalose hydrolysis activity of the recombinant Saci_1816 was observed at $\mathrm{pH} 4.0$ and $60^{\circ} \mathrm{C}$. The $\mathrm{pH}$ dependence of the recombinant enzyme was similar to that of the native enzyme, but its optimal temperature was $20-25^{\circ} \mathrm{C}$ lower, and its thermostability was also slightly reduced. From the biochemical and structural results, Saci_1816 was identified as a trehalase responsible for trehalose degradation in S. acidocaldarius. Identification of the treH gene confirms that the degradation of trehalose in Sulfolobus species occurs via the TreH pathway.

Keywords: Glycoside hydrolase family 15, Sulfolobus acidocaldarius, trehalase, trehalose

\section{Introduction}

Extremophilic microorganisms accumulate osmolytes to sustain equilibrium during times of environmental stress. Compatible solutes are materials that are not used in metabolism and make it possible to adjust intracellular turgor pressure and stabilize macromolecules under heat and salt stress [1]. Sulfolobus acidocaldarius is a thermoacidophilic archaeon that grows in temperatures ranging $70-90^{\circ} \mathrm{C}$. Accumulation of trehalose has been reported in Sulfolobus species [2, 3]. However, the physiological role of trehalose has not yet been confirmed. Trehalose has been proposed to play a role as an osmo- and thermoprotectant. A two-step TreYZ pathway (from starch to trehalose) for trehalose synthesis was reported in S. acidocaldarius [4]. The genes tre $Y$ and tre $Z$ were identified, and their maltooligosyltrehalose synthase and maltooligosyltrehalose trehalohydrolase activities were confirmed [4-12]. Furthermore, a homolog of trehalose glycosyltransferring synthase (TreT), which can catalyze the reversible formation of trehalose from glucose and NDP-glucose, was also found, but the biochemical properties of this enzyme were not elucidated [13]. There have been several descriptions of trehalose synthesis in Sulfolobus species; however, the pathway for degradation of trehalose in this organism has not been studied. It has been proposed that TreT may be involved in degrading trehalose in Thermococcus litoralis; however, the activity that hydrolyzes trehalose into glucose and NDP-glucose has not been confirmed [14, 15]. In our previous study, we reported that the cell-free extracts of S. acidocaldarius showed trehalase (TreH) activity, indicating that this species can degrade intracellular trehalose via the TreH pathway [16]. TreH hydrolyzes trehalose into two glucose molecules without the aid of a cofactor. Most of trehalases have been classified as a member of the glycoside hydrolase 37 (GH37) family and GH65 family in the Carbohydrate-Active enZYmes database (CAZy; http:// www.cazy.org/). However, no putative genes encoding 
GH37 or GH65 family trehalases were detected in the S. acidocaldarius genome. Recently, a new type of trehalase assigned to the GH15 family has been identified in Thermoplasma species [17]. Based on the primary structure, Thermoplasma trehalases are more similar to glucoamylases from the identical GH15 family than to trehalases classified to the GH37 and GH65 families. Nonetheless, GH15 family enzymes share a common $\alpha$-helix-rich catalytic domain designated the $(\alpha / \alpha)_{6}$ barrel, similar to GH37 and GH65.

In this study, the gene encoding the enzyme responsible for TreH activity was identified, and TreH activity was confirmed by expressing the recombinant enzyme in Escherichia coli. The properties of this recombinant enzyme were examined by comparison with those of the native enzyme.

\section{Materials and Methods}

\section{Strains and Growth Conditions}

E. coli $\mathrm{DH} 5 \alpha$ and C43(DE3) cells harboring pRIL were used for cloning and overexpression, respectively. They were aerobically grown at $37^{\circ} \mathrm{C}$ in Luria-Bertani (LB) broth or LB agar plates. The medium for the C43(DE3)pRIL strain was supplemented with kanamycin $(30 \mu \mathrm{g} / \mathrm{ml})$ and chloramphenicol $(30 \mu \mathrm{g} / \mathrm{ml})$. S. acidocaldarius strains were aerobically grown in a shaking incubator $\left(77^{\circ} \mathrm{C}, 180 \mathrm{rpm}\right)$ in YT medium with $0.005 \%$ yeast extract $(\mathrm{w} / \mathrm{v})$ and $0.1 \%$ tryptone $(\mathrm{w} / \mathrm{v})$, supplemented with Brock's mineral salts. The composition of Brock's mineral salts was the following: $\left(\mathrm{NH}_{4}\right)_{2} \mathrm{SO}_{4}, 1.3 \mathrm{~g} ; \mathrm{MgSO}_{4} \cdot 7 \mathrm{H}_{2} \mathrm{O}, 0.25 \mathrm{~g} ; \mathrm{KH}_{2} \mathrm{PO}_{4}, 0.28 \mathrm{~g}$; $\mathrm{CaCl}_{2} \cdot 2 \mathrm{H}_{2} \mathrm{O}$ ， $0.07 \mathrm{~g} ; \mathrm{FeCl}_{3} \cdot 6 \mathrm{H}_{2} \mathrm{O} ， 0.02 \mathrm{~g} ; \mathrm{MnCl}_{2} \cdot 4 \mathrm{H}_{2} \mathrm{O}$ ， $1.8 \mathrm{mg}$; $\mathrm{CuCl}_{2} \cdot 2 \mathrm{H}_{2} \mathrm{O}, 0.05 \mathrm{mg} ; \mathrm{ZnSO}_{4} \cdot 7 \mathrm{H}_{2} \mathrm{O}, 0.22 \mathrm{mg} ; \mathrm{NaMoO}_{4} \cdot 2 \mathrm{H}_{2} \mathrm{O}, 0.03 \mathrm{mg}$; $\mathrm{VoSO}_{4} \cdot \mathrm{H}_{2} \mathrm{O}, 0.03 \mathrm{mg} ; \mathrm{NiSO}_{4}, 5 \mu \mathrm{g} ; \mathrm{CoSO}_{4} \cdot 7 \mathrm{H}_{2} \mathrm{O}, 0.01 \mathrm{mg}$; and $\mathrm{Na}_{2} \mathrm{~B}_{4} \mathrm{O}_{7} \cdot 10 \mathrm{H}_{2} \mathrm{O}, 4.5 \mu \mathrm{g}$. The $\mathrm{pH}$ was adjusted to 3.3 with $6 \mathrm{M}$ $\mathrm{H}_{2} \mathrm{SO}_{4}$ before sterilization.

\section{Cloning of Putative treH Genes from S. acidocaldarius}

The primer sequences for Saci_1816 were the following: forward, 5'-TACATATGTTAGGTATGAAACCTCTAGGAT-3'; reverse, 5' TACTCGAGTGTACTTAGACCTTTTACT-3'. The primer sequences for Saci_1250 were as follows: forward, $5^{\prime}$-TTCATATGAATTACG CCTTACTTTCAAACG-3'; reverse, 5' -TCCTCGAGTCTTACTTCA TCAAACTC-3'. All forward and reverse primers contained NdeI and XhoI recognition sites (underlined). Genomic DNA of S. acidocaldarius DSM639 was used as a template. To amplify the saci_1816 and saci_1250 genes, PCR was performed as follows: 1 cycle at $94^{\circ} \mathrm{C}$ for $5 \mathrm{~min}$, followed by 30 cycles of $98^{\circ} \mathrm{C}$ for $10 \mathrm{sec}$, $55^{\circ} \mathrm{C}$ for $5 \mathrm{sec}$, and $72^{\circ} \mathrm{C}$ for $110 \mathrm{sec}$. The reaction mixture contained 10 pmol of the forward and reverse primers and $1.25 \mathrm{U}$ of PrimeSTAR HS DNA Polymerase (TaKaRa Bio Inc., Korea). The PCR products were purified using a PCR Purification Kit (Elpis Biotech Inc., Korea) and digested with NdeI and XhoI. The digested DNA fragments were inserted into the pET29b(+) plasmid, and the recombinant vectors were transformed into the E. coli C43(DE3)pRIL strain. The transformants were selected with kanamycin and chloramphenicol.

\section{Overexpression and Purification of Recombinant TreH}

The recombinant $E$. coli cells were grown overnight at $37^{\circ} \mathrm{C}$ in LB medium containing kanamycin $(30 \mu \mathrm{g} / \mathrm{ml})$ and chloramphenicol $(30 \mu \mathrm{g} / \mathrm{ml})$, and then an inoculum was added to fresh LB medium to a final concentration of $1 \%(\mathrm{v} / \mathrm{v})$, also with kanamycin and chloramphenicol at $1 \%$ of the volume of the culture medium $(\mathrm{v} / \mathrm{v})$. Cells were grown at $37^{\circ} \mathrm{C}$ to an optical density at $600 \mathrm{~nm}$ of 0.4 . The expression of each protein was induced by the addition of $0.1 \mathrm{M}$ isopropyl-1-thio- $\beta$-D-galactopyranoside (IPTG), and then the cells were grown for an additional $5 \mathrm{~h}$ at $30^{\circ} \mathrm{C}$. Cells were harvested by centrifugation $\left(6,000 \times g\right.$ for $50 \mathrm{~min}$ at $\left.4^{\circ} \mathrm{C}\right)$ and resuspended in $20 \mathrm{mM}$ sodium phosphate $(\mathrm{pH} 7.4)$ containing $0.5 \mathrm{M} \mathrm{NaCl}$ and $20 \mathrm{mM}$ imidazole. Cells were then lysed by sonication at $200 \mu \mathrm{A}$ for 7-9 min (Ultrasonic homogenizer US300T; Tender Scientific Co., Ltd., Taiwan) on ice and centrifuged at 3,000 $\times g$ for $10 \mathrm{~min}$ to remove the cell debris. Insoluble proteins were removed by centrifugation at $16,000 \times g$ for $40 \mathrm{~min}$ at $4^{\circ} \mathrm{C}$. The supernatants were filtered using a $0.45-\mu \mathrm{m}$ syringe filter and heated to $60^{\circ} \mathrm{C}$ for $30 \mathrm{~min}$ to remove heat-labile E. coli proteins by centrifugation at $3,000 \times g$ for $50 \mathrm{~min}$. The soluble proteins were then subjected to Ni Sepharose High Performance (GE Healthcare, UK) affinity chromatography. The fractions containing the recombinant proteins were analyzed by SDS-PAGE.

\section{Activity Assays}

For the TreH activity assay, a reaction mixture (500 $\mu$ l) containing $5 \mathrm{mM}$ trehalose and the enzyme solution $(1.5 \mu \mathrm{g})$ in $20 \mathrm{mM}$ sodium citrate buffer ( $\mathrm{pH} 4.0$ ) was incubated for $30 \mathrm{~min}$ at $60^{\circ} \mathrm{C}$, and then the reaction was stopped by boiling for $10 \mathrm{~min}$. The amount of glucose generated by the enzyme reaction was measured in a glucose oxidase-peroxidase (GOP) assay at $37^{\circ} \mathrm{C}$ for $30 \mathrm{~min}$. Glucose in the reaction mixture $(50 \mu \mathrm{l})$ was quantified by coupling the production of gluconic acid and hydrogen peroxide to the oxidation of $o$-dianisidine, using glucose oxidase and peroxidase in the GOP assay kit $(100 \mu \mathrm{l})$ to form a colored product. The amount of increase in absorption at $540 \mathrm{~nm}$ is proportional to the glucose concentration. One unit of enzyme activity is defined as $1 \mu \mathrm{mol}$ of glucose formed per minute under standard assay conditions. The $\mathrm{pH}$ dependence of the purified enzyme for TreH activity was determined at $60^{\circ} \mathrm{C}$ and at a $\mathrm{pH}$ of 3.0-8.5 using the

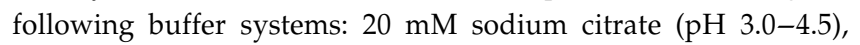
sodium acetate ( $\mathrm{pH} 4.5-5.5)$, sodium phosphate ( $\mathrm{pH} 5.5-7.5)$, and Tris- $\mathrm{HCl}$ ( $\mathrm{pH} 7.5-8.5)$. The temperature dependence was determined in $20 \mathrm{mM}$ sodium citrate $(\mathrm{pH} 4.0)$ buffer and at $40-90^{\circ} \mathrm{C}$ for $30 \mathrm{~min}$. The thermostability of the enzyme was determined by incubating the enzyme solution $(1.5 \mu \mathrm{g})$ in $20 \mathrm{mM}$ sodium citrate ( $\mathrm{pH} 4.0$ ) buffer at temperatures ranging from $60^{\circ} \mathrm{C}$ to $90^{\circ} \mathrm{C}$. To examine the hydrolytic patterns of the putative $\mathrm{TreH}$, the enzyme 
solution $(1.5 \mu \mathrm{g})$ in $20 \mathrm{mM}$ sodium citrate $(\mathrm{pH} 4.0)$ buffer was incubated with $5 \mathrm{mM}$ trehalose at $60^{\circ} \mathrm{C}$.

\section{Thin-Layer Chromatography (TLC) Analysis}

The reaction products and their respective standard solutions were applied to silica plates (type $60 \mathrm{~F}_{254}$; Merck, Germany), which were subsequently developed with 1-butanol:acetic acid:water $(7: 4: 1(\mathrm{v} / \mathrm{v} / \mathrm{v}))$. The developed TLC plates were completely dried and then visualized by dipping them in a solution containing $0.3 \%$ (w/v) $\mathrm{N}$-(1-naphthyl)-ethylenediamine and 5\% (v/v) $\mathrm{H}_{2} \mathrm{SO}_{4}$ in methanol, followed by heating at $120^{\circ} \mathrm{C}$ for $5 \mathrm{~min}$.

\section{Partial Purification of Native TreH from Sulfolobus acidocaldarius}

The purification of native TreH was slightly modified as described previously [16]. S. acidocaldarius DSM639 was grown at $77^{\circ} \mathrm{C}$ in YT medium supplemented with $0.2 \%(\mathrm{w} / \mathrm{v})$ glucose. Cells were harvested in the late exponential growth stage, washed twice with buffer ( $50 \mathrm{ml}$ of $20 \mathrm{mM}$ sodium phosphate, $\mathrm{pH} 7.4$ ), and resuspended in $100 \mathrm{ml}$ of the same buffer. After sonication, cell lysates were centrifuged at 3,000 $\times g$ for $10 \mathrm{~min}$ to remove the cell debris. This cell crude extract was loaded onto a HiTrap DEAE fast flow $5 \mathrm{ml}$ column (GE Healthcare, USA). The column was washed with the same buffer used in cell resuspension, and the bound proteins were eluted at a linear gradient of $0-0.5 \mathrm{M}$ $\mathrm{NaCl}$ by AKTA prime FPLC (GE Healthcare, USA). All proteins were separated in each $5 \mathrm{ml}$ fraction and trehalose hydrolyzing activity was measured. The fractions showing trehalose hydrolyzing activity were collected and further applied to HiLoad 16/600 Superdex 200 pg (GE Healthcare, USA) size-exclusion chromatography. The active fractions were collected and desalted on a HiPrep 26/10 desalting column (GE Healthcare, USA) with cell resuspension buffer ( $20 \mathrm{mM}$ sodium phosphate, $\mathrm{pH}$ 7.4). The desalted proteins were applied to a HiTrap Q HP $1 \mathrm{ml}$ column (GE Healthcare, USA) equilibrated with cell resuspension buffer. After washing, the bound proteins were eluted with a linear gradient of $0-0.5 \mathrm{M}$ $\mathrm{NaCl}$. All proteins were separated in $1 \mathrm{ml}$ fractions and the fractions exhibiting trehalose hydrolyzing activity were used as partially purified trehalase, which was used for mass spectrometry analysis for the identification of the gene for TreH.

\section{Molecular Mass Determination of Native TreH}

To estimate the molecular mass of native TreH and recombinant TreH, size-exclusion chromatography was performed. The AKTA prime FPLC and HiLoad 16/600 Superdex 200 pg column were used. Gel filtration marker kit MWGF1000 (Sigma-Aldrich, USA) was used as the molecular weight standard according to the manufacturer's instruction. All running conditions were the same as follows: flow rate, $1 \mathrm{ml} / \mathrm{min}$; fraction size, $5 \mathrm{ml}$.

\section{Mass Spectrometry (MS) Analysis}

In-gel pieces were decolorized by reacting in $50 \%(\mathrm{v} / \mathrm{v})$ acetonitrile (ACN) solvent for $15 \mathrm{~min}$. The chymotrypsin and trypsin solutions $(1 \mu \mathrm{g})$ were added to the decolorized in-gel piece samples and incubated at $37^{\circ} \mathrm{C}$ for $16 \mathrm{~h}$. Then, $2 \mu \mathrm{l}$ of $1 \mathrm{M}$ dithiothreitol was added and the pieces were stored at room temperature for $1 \mathrm{~h}$, and then $4 \mu \mathrm{l}$ of $1 \mathrm{M}$ iodoacetamide was added and the samples were further incubated at room temperature for $1 \mathrm{~h}$. Finally, $200 \mu \mathrm{l}$ of $50 \%(\mathrm{v} / \mathrm{v}) \mathrm{ACN}$ solvent was added to recover the hydrolyzed peptide through gel dehydration. The samples were dried using a SpeedVac (Thermo Fisher Scientific, USA). Solid-phase extraction was performed using Sep-Pak (Waters, USA) and then drying again using SpeedVac. Then, $15 \mu \mathrm{l}$ of water containing $0.1 \%(\mathrm{v} / \mathrm{v})$ formic acid was added and the sample was kept refrigerated until analysis.

For LC-MS/MS, a Q Exactive HF Hybrid Quadrupole-Orbitrap Mass Spectrometer (Thermo Fisher Scientific, USA) was used. The MS was coupled with an UHPLC Ultimate 3000 (Dionex, Germany) system and peptide separation was proceeded on an Acclaim PepMap RSLC C18 column $(2 \mu \mathrm{m}, 100 \AA$, $75 \mu \mathrm{m} \times 15$ cm, nanoViper; Dionex, Germany). The samples were eluted in gradient mode at a flow rate of $0.3 \mu \mathrm{l} / \mathrm{min}$ as follows: $5 \% \mathrm{~B}$ at $0-5 \mathrm{~min} ; 5-30 \% \mathrm{~B}$ at $5-$ $33 \mathrm{~min} ; 30-50 \% \mathrm{~B}$ at $33-38 \mathrm{~min} ; 50-80 \% \mathrm{~B}$ at $38-40 \mathrm{~min} ; 80 \% \mathrm{~B}$ at $40-43 \mathrm{~min} ; 80-5 \% \mathrm{~B}$ at $43-45 \mathrm{~min}$; and $5 \% \mathrm{~B}$ at $45-59 \mathrm{~min}$. The mobile phase was water containing $0.1 \%(\mathrm{v} / \mathrm{v})$ formic acid (solvent $\mathrm{A}$ ) and $\mathrm{ACN}$ containing $0.1 \%(\mathrm{v} / \mathrm{v})$ formic acid (solvent B) and the injection volume was $1 \mu \mathrm{l}$. The MS conditions were set as follows: spray voltage, $+2,500 \mathrm{~V}$; capillary temperature, $300^{\circ} \mathrm{C}$. Peptides were scanned at $\mathrm{m} / \mathrm{z} 150$ to 1,800 . LC-MS/MS data were evaluated using Thermo Proteome Discoverer 2.1.0.81 (Thermo Fisher Scientific, USA).

\section{Results}

Comparison of the Amino Acid Sequences of Saci_1816 and Saci_1250 with Those of Other Archaeal TreHs

Two putative TreHs, Saci_1250 and Saci_1816, were selected as enzyme candidates responsible for trehalose degradation in S. acidocaldarius. Saci_1816 showed 43\% sequence identity with Saci_1250. Sequence alignments with two TreHs, Ta0286 (Thermoplasma acidophilum TreH) and MSMEG_4535 (Mycobacterium smegmatis trehalase), revealed five conserved regions found in GH15 family TreHs [17, 18]. Two glutamic acid residues of Saci_1816, Glu374 and Glu524, in regions 3 and 5, which are known as catalytic residues in this family, were also conserved. This suggested that both candidates may possess TreH activity (Fig. 1).

\section{Saci_1816 Showed TreH Activity}

To determine which protein possessed TreH activity, two candidate genes were cloned into the pET29b vector, and the resulting plasmids were introduced into E. coli. Both proteins were expressed as a soluble protein when the transformed cells were induced by IPTG, and each protein 


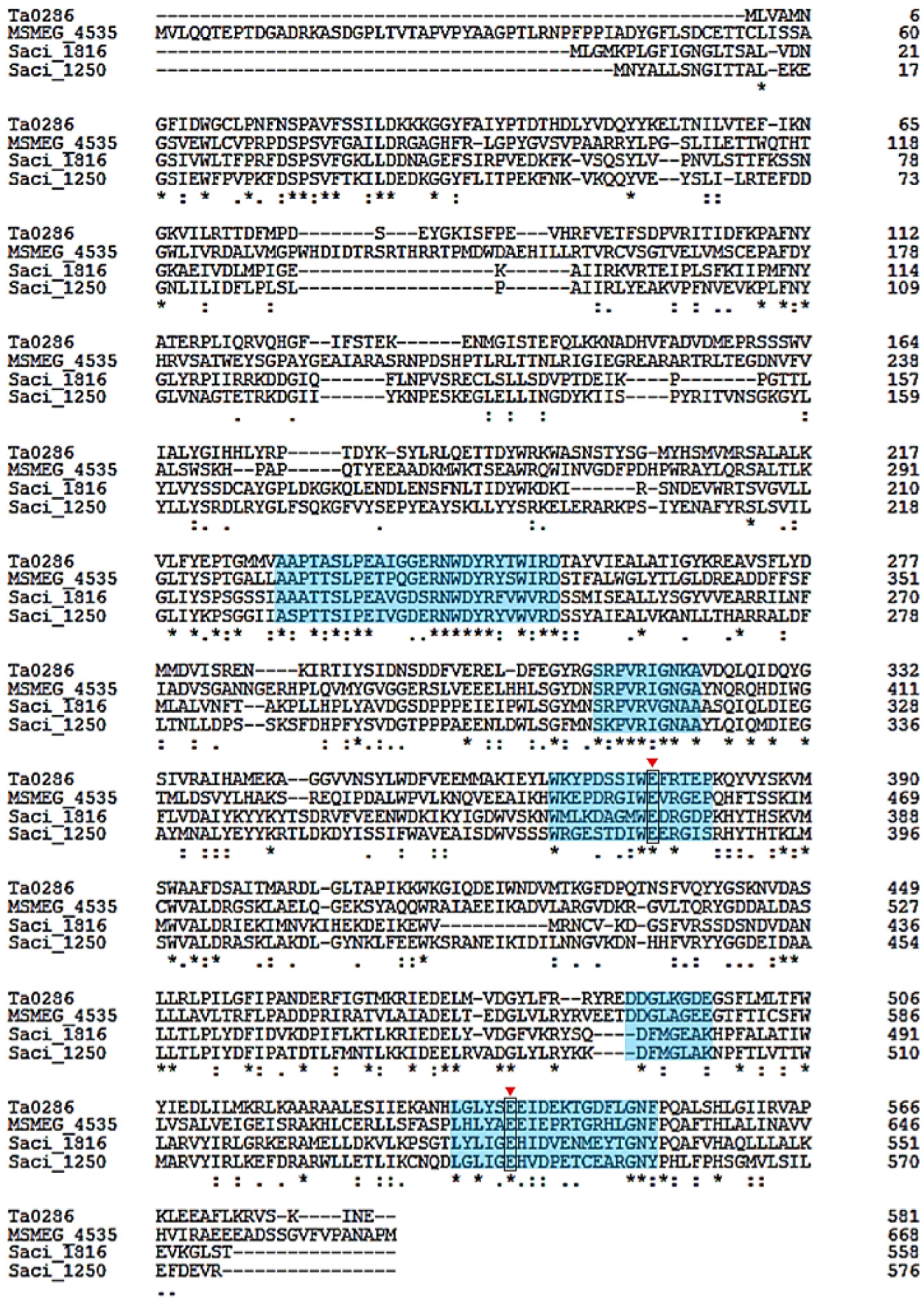

Fig. 1. Alignment of Saci_1816 and Saci_1250 sequences with those of other bacterial and archaeal trehalases.

Ta0286, Thermoplasma acidophilum trehalase; MSMEG_4535, Mycobacterium smegmatis trehalase. Blue and black boxes represent the five highly conserved regions of GH15 trehalases and two catalytic residues (nucleophile and acid/base) in the active site, respectively. Multiple sequences were aligned using the UniProt alignment program (http://www.uniprot.org/align/).

was purified by Ni-NTA affinity chromatography. SDSPAGE analysis of each purified recombinant protein showed a single band with an apparent molecular mass of $63.6 \mathrm{kDa}$ (Fig. 2A), which agreed with the expected size based on the primary structure. To examine TreH activity, the purified proteins were incubated with trehalose at $60^{\circ} \mathrm{C}$, and the reaction products were examined by TLC. As shown in Fig. 2B, glucose was released from trehalose by 

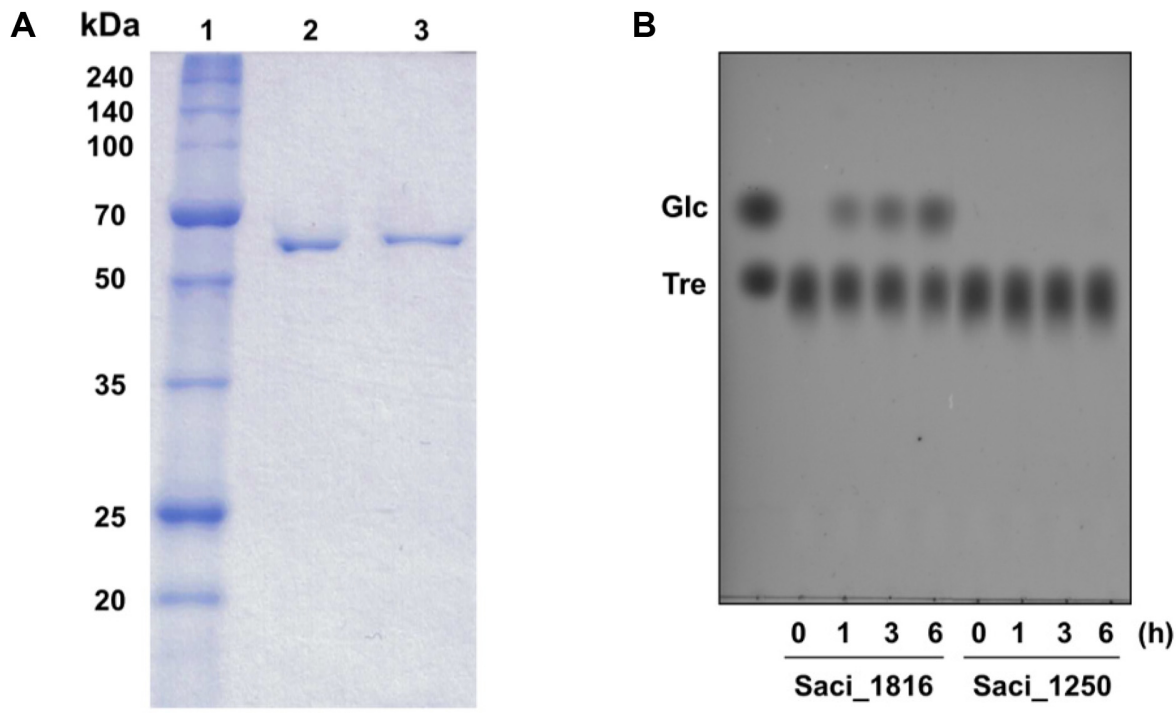

Fig. 2. Purification of recombinant Saci_1816 and Saci_1250.

(A) Sodium dodecyl sulfate polyacrylamide gel electrophoresis of purified proteins. Lane 1, molecular mass marker; lane 2, Saci_1816; lane 3, Saci_1250. (B) Thin-layer chromatogram of the products of the enzyme reaction in $20 \mathrm{mM}$ sodium citrate ( $\mathrm{pH} 4.0)$ with $5 \mathrm{mM}$ trehalose at $60^{\circ} \mathrm{C}$.

the enzyme reaction. Saci_1816 alone showed TreH activity; Saci_1250 did not. This indicated that saci_1816 encodes a TreH responsible for trehalose degradation in S. acidocaldarius.

\section{Characterization of the Recombinant Saci_1816}

The recombinant TreH (Saci_1816) hydrolyzed trehalose specifically; it did not hydrolyze any other trehalose analogs such as maltose, nigerose, and turanose. The enzyme showed typical TreH properties. The $\mathrm{pH}$ and temperature dependence of the recombinant $\mathrm{TreH}$ were examined. The optimal $\mathrm{pH}$ of the recombinant TreH for trehalose was 4.0, and the activity profiles at various $\mathrm{pHs}$ were very similar to those of native TreH from S. acidocaldarius (Fig. 3A) [16]. However, the optimal temperature $\left(60^{\circ} \mathrm{C}\right)$ and thermostability (half-life of $41 \mathrm{~min}$ at $90^{\circ} \mathrm{C}$ ) were decreased compared with those of native TreH (Figs. 3B and 3C). Previously, the optimal activity of native TreH was observed at approximately 80$85^{\circ} \mathrm{C}$, with a half-life of $53 \mathrm{~min}$ at $90^{\circ} \mathrm{C}$. To investigate the differences in the thermal properties of recombinant and native TreH, size-exclusion chromatography of both proteins was performed. The trehalose hydrolyzing activity of the partially purified native TreH was detected in the proteins near $190 \mathrm{kDa}$ molecular size (Fig. 4A). Unexpectedly, the purified recombinant TreH showed two different forms despite one band being seen in SDS-PAGE. One form was close to $200 \mathrm{kDa}$, which is similar to native TreH, and the other was nearly $480 \mathrm{kDa}$ in size (Fig. 4B). Based on this result, the native form of TreH was expected to be a trimer. The two different forms observed in the recombinant TreH are presumably due to the mixture with incompletely folded proteins.

\section{Saci_1816 Is Indeed TreH}

In our previous study, the molecular mass of native TreH was estimated to be $40 \mathrm{kDa}$ [16]. If the molecular mass of the previous protein was correct, the molecular mass of the recombinant TreH observed in this study is too large. To confirm this discrepancy, MALDI-TOF analysis of the protein previously assessed with TreH was performed and the protein was found to be a glutamate dehydrogenase (Saci_0155, 46.2 kDa) (data not shown). Attempts to purify native TreH to homogeneity failed. Instead, the enzyme partially purified by three consecutive chromatographic steps was examined by SDS-PAGE, and the bands close to $65 \mathrm{kDa}$, similar to the predicted molecular mass of recombinant TreH, were subjected to LC-MS/MS analysis to identify the correct trehalase-encoding gene. MS/MS analysis of the three different protein bands identified the $\sim 65 \mathrm{kDa}$ protein as the predicted trehalase Saci_1816 (Fig. 5 band 1 and Table 1). The $\sim 60$ and $\sim 53 \mathrm{kDa}$ proteins were also detected and corresponded to acetolactate synthase (Saci_2281) (Fig. 5 band 2 and Table 1) and phosphoenolpyruvate carboxylase (Saci_0059) or phosphoribosylamineglycine ligase (Saci_1613) (Fig. 5 band 3, Table 1). 
A

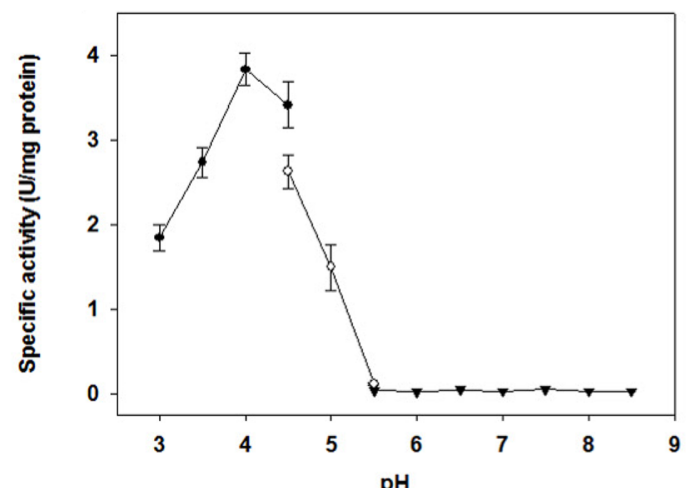

B

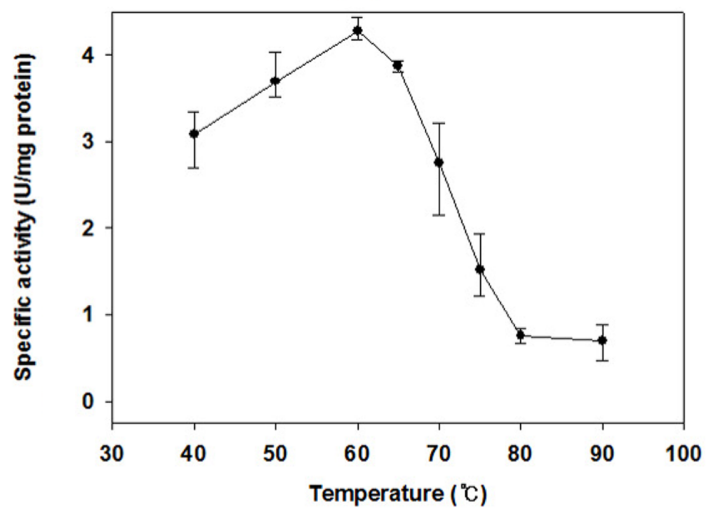

C

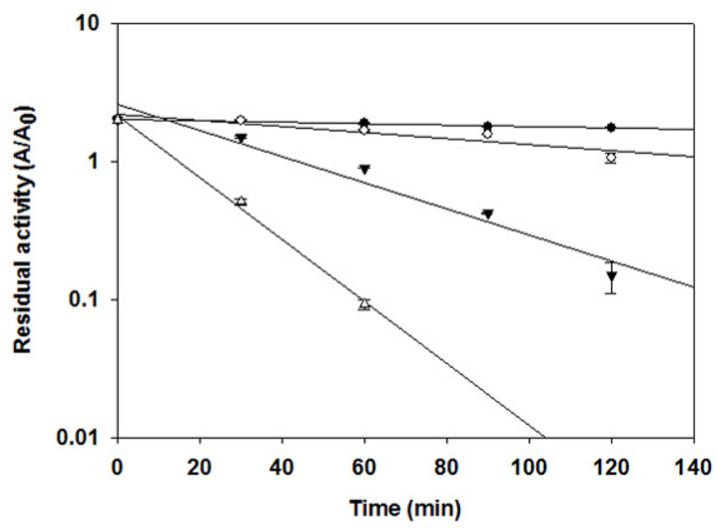

Fig. 3. Effects of $\mathrm{pH}(\mathbf{A})$ and temperature (B) on the activity and thermostability $(\mathbf{C})$ of the recombinant TreH.

(A) To determine the optimal $\mathrm{pH}$, the following buffers were used: $\mathrm{pH} 3.0-4.5$, sodium citrate (closed circles); $\mathrm{pH} 4.5-5.5$, sodium acetate (open circles); $\mathrm{pH} 5.5-7.5$, sodium phosphate (open triangles); and $\mathrm{pH} 7.5-8.5$, Tris- $\mathrm{HCl}$ (closed triangles). Activity was assayed at $60^{\circ} \mathrm{C}$ for $30 \mathrm{~min}$ in the various buffers $(20 \mathrm{mM})$. (B) To determine the optimal temperature, activity was measured at the indicated temperatures under standard assay conditions. (C) To determine thermostability, the enzyme was incubated at $60^{\circ} \mathrm{C}$ (closed circles), $75^{\circ} \mathrm{C}$ (open circles), $80^{\circ} \mathrm{C}$ (closed triangles), and $90^{\circ} \mathrm{C}$ (open triangles) in $20 \mathrm{mM}$ sodium citrate buffer ( $\mathrm{pH} 4.0)$ without the substrate, and the residual activity was measured as above. Error bars represent the standard deviation from three separate experiments. $\mathrm{A}_{\mathrm{o}}$ and $\mathrm{A}$ are the initial and residual activities, respectively, of the enzyme after incubation for the indicated time periods.
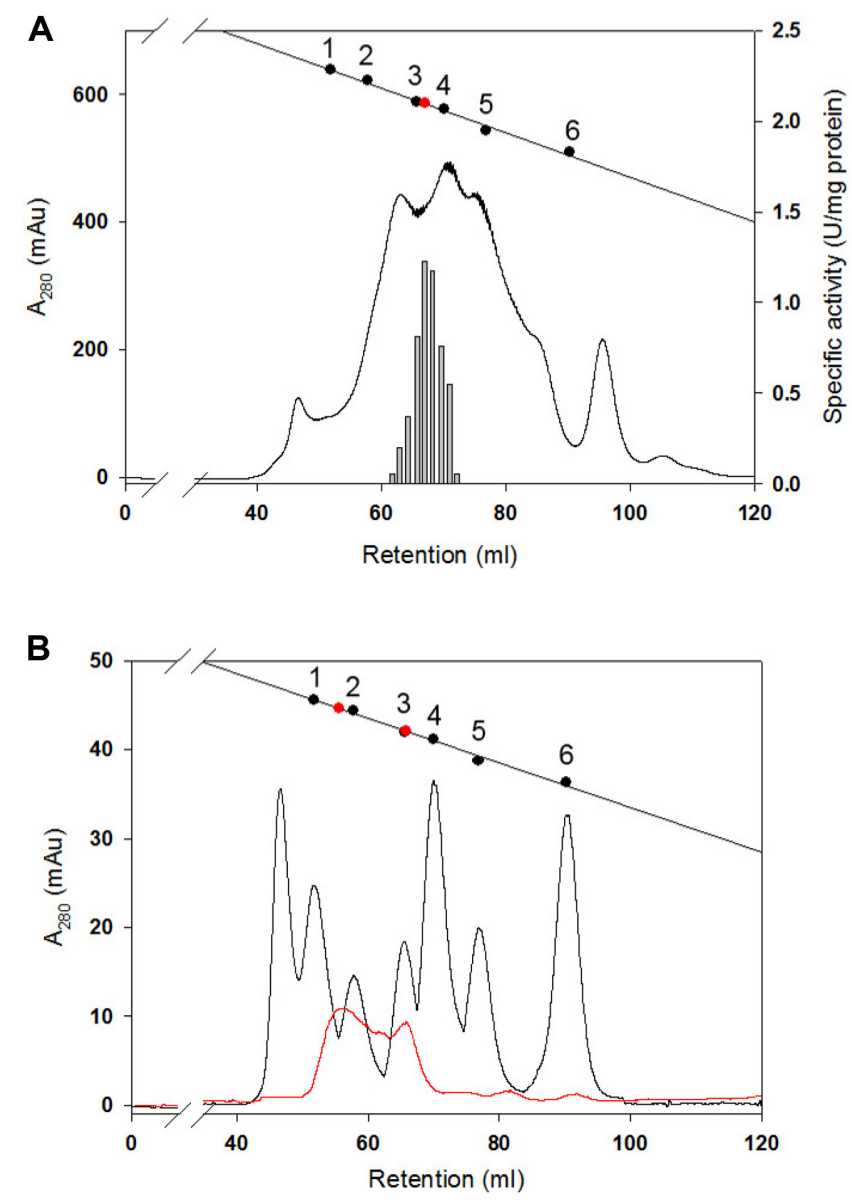

Fig. 4. Molecular mass determination of native (A) and recombinant TreH (B) by size-exclusion chromatography.

The trehalose hydrolyzing activity (gray bar) was measured using trehalose as a substrate and the maximum activity and $\mathrm{TreH}$ peak are marked (red dot). TreH and six molecular mass standard proteins were each subjected to size-exclusion chromatography. The molecular mass of TreH was estimated by comparing the retention time of TreH with the standard curve obtained for the molecular mass standard proteins. 1, Tyroglobulin (669 kDa); 2, apoferritin (443 kDa); 3, $\beta$ amylase $(200 \mathrm{kDa}) ; 4$, alcohol dehydrogenase $(150 \mathrm{kDa}) ; 5$, bovine serum albumin (66 kDa); 6, carbonic anhydrase (29 kDa).

\section{Discussion}

The aim of this study was to identify the gene encoding the TreH that is responsible for trehalose degradation in S. acidocaldarius. S. acidocaldarius produces trehalose as a compatible solute during salinity stress conditions. Previously, we reported that degradation of accumulated trehalose was performed by intracellular $\mathrm{TreH}$ that hydrolyzed trehalose into two glucose molecules [16]. However, the search for a gene encoding TreH was not 


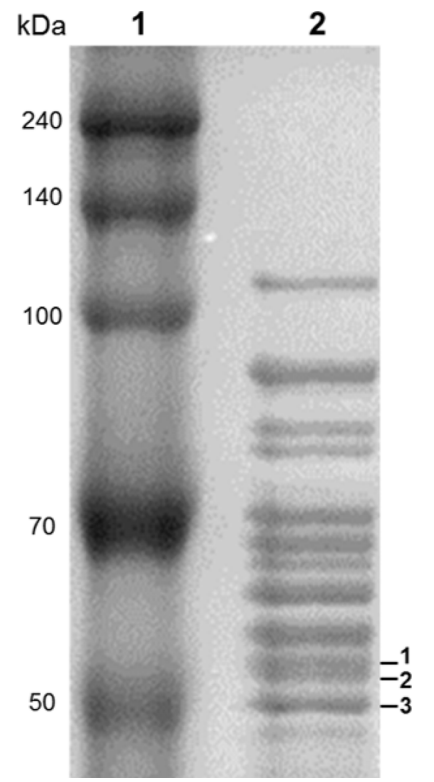

Fig. 5. SDS-PAGE analysis of partially purified native TreH. The proteins numbered were selected on the basis of trehalose hydrolyzing activity and the expected $\mathrm{TreH}$ molecular weight and analyzed by mass spectrometry. Lane 1, size marker for protein; lane 2 , partially purified native TreH.

successful because GH35 or GH65 family-type TreHs were not detected in a whole-genome analysis. GH15 familytype TreHs have recently been reported in the archaea Thermoplasma volcanium and T. acidophilum [17]. Three GH15-type genes (saci_1198, saci_1250, and saci_1816) were found in the S. acidocaldarius genome. The saci_1198 gene product showed $56 \%$ and $52 \%$ amino acid sequence identities with glucoamylases of Picrophilus torridus DSM9790 and T. volcanium GSS1, respectively, indicating that Saci_1198 is a GH15 glucoamylase (unpublished data). The high similarities of the deduced amino acid sequences of Saci_1250 and Saci_1816 and those of known thermophilic TreHs implied that one of the two proteins could be a TreH in this organism.

Both proteins were heterologously expressed and purified in E. coli, and their trehalose hydrolyzing activities were examined using trehalose as a substrate. Saci_1816 exhibited TreH activity but Saci_1250 did not. The $\mathrm{pH}$ profile of recombinant Saci_1816 showed a narrow acidic $\mathrm{pH}$ range and high thermostability, consistent with the properties of native TreH in S. acidocaldarius. The low optimal temperature and relatively low thermal stability seen in recombinant TreH are considered to be due to incomplete folding of the recombinant protein, as shown by the results of size-exclusion chromatography. A decrease in the optimal temperature and reduced thermostability have been observed in other exogenous proteins expressed in E. coli. Recombinant MalA expressed in E.coli was previously reported to be highly unstable and exhibited optimal activity at $20^{\circ} \mathrm{C}$ below that of the native enzyme expressed in S. acidocaldarius [19]. MS analysis of partially purified native TreH confirmed that Saci_1816 is the only trehalase in S. acidocaldarius. As a result, Saci_1816 is considered to be the TreH that is responsible for trehalose degradation in this organism.

In hyperthermophilic archaea, the degradation pathway for intracellularly accumulated trehalose during cell growth has not been well characterized. Based on sequence homology data, the TreP, TreT, or TreH pathways are the expected routes for trehalose degradation. TreT has been reported to degrade trehalose in Thermococcus litoralis and Pyrococcus horikoshii [14, 20]. Recently, the TreH pathway was also identified in thermophilic Thermoplasma species [17]. Although a putative TreT (Saci_1827) was found in S. acidocaldarius, trehalose degradation activity was not observed [16]. The identification of TreH in this organism, as well as in Thermoplasma species, implies that the TreH pathway may be the only route to trehalose degradation in thermoacidophilic archaea. To date, GH15-type TreHs have only been found in thermoacidophilic archaea, and their crystal structures have not yet been solved. Elucidation of these structures will be important to understand the detailed reaction mechanism of trehalose degradation in these archaeal groups.

Table 1. Mass spectrometry analysis of the native TreH with SDS gel ${ }^{\mathrm{a}}$.

\begin{tabular}{cllccc}
\hline Band & ORF no. & \multicolumn{1}{c}{ Annotation } & MW (kDa) & Peptide count & Protein coverage (\%) \\
\hline 1 & saci_1816 & Glycosyl hydrolase & 63.6 & 65 & 65.8 \\
2 & saci_2281 & Acetolactate synthase & 59.3 & 18 & 34.7 \\
3 & saci_0059 & Phosphoenolpyruvate carboxylase & 58.4 & 39 & 65.9 \\
& saci_1613 & Phosphoribosylamine-glycine ligase & 52.9 & 28 & 58.8 \\
\hline
\end{tabular}

${ }^{a}$ Protein bands were excised from the SDS gel of the fraction with trehalose degradation activity after partial purification as described in Materials and Methods. Protein bands 1 to 3, as depicted in Fig. 5, were isolated and identified by LC-MS/MS. 


\section{Acknowledgments}

This research was supported by the Basic Science Research Program through the National Research Foundation of Korea (NRF), funded by the Ministry of Science, ICT and Future Planning (NRF-2016R1A2B4011554).

\section{Conflict of Interest}

The authors have no financial conflicts of interest to declare.

\section{References}

1. da Costa MS, Santos H, Galinski EA. 1998. An overview of the role and diversity of compatible solutes in bacteria and archaea. Adv. Biochem. Eng. Biotechnol. 61: 117-153.

2. Martins LO, Huber R, Huber H, Stetter KO, Da Costa MS, Santos H. 1997. Organic solutes in hyperthermophilic archaea. Appl. Environ. Microbiol. 63: 896-902.

3. Nicolaus B, Gambacorta A, Basso AL, Riccio R, Derosa M, Grant WD. 1988. Trehalose in Archaebacteria. Syst. Appl. Microbiol. 10: 215-217.

4. Maruta K, Mitsuzumi H, Nakada T, Kubota M, Chaen H, Fukuda S, et al. 1996. Cloning and sequencing of a cluster of genes encoding novel enzymes of trehalose biosynthesis from thermophilic archaebacterium Sulfolobus acidocaldarius. Biochim. Biophys. Acta 1291: 177-181.

5. Di Lernia I, Morana A, Ottombrino A, Fusco S, Rossi M, De Rosa M. 1998. Enzymes from Sulfolobus shibatae for the production of trehalose and glucose from starch. Extremophiles 2: 409-416.

6. Gueguen Y, Rolland JL, Schroeck S, Flament D, Defretin S, Saniez MH, Dietrich J. 2001. Characterization of the maltooligosyl trehalose synthase from the thermophilic archaeon Sulfolobus acidocaldarius. FEMS Microbiol. Lett. 194: 201-206.

7. Kobayashi K, Kato M, Miura Y, Kettoku M, Komeda T, Iwamatsu A. 1996. Gene cloning and expression of new trehalose-producing enzymes from the hyperthermophilic archaeum Sulfolobus solfataricus KM1. Biosci. Biotechnol. Biochem. 60: 1882-1885.

8. Mukai K, Tabuchi A, Nakada T, Shibuya T, Chaen H, Fukuda S, et al. 1997. Production of trehalose from starch by thermostable enzymes from Sulfolobus acidocaldarius. Starch 49: 26-30.

9. de Pascale D, Sasso MP, Di Lernia I, Di Lazzaro A, Furia A,
Farina MC, et al. 2001. Recombinant thermophilic enzymes for trehalose and trehalosyl dextrins production. J. Mol. Catal. B Enzym. 11: 777-786.

10. Fang TY, Hung XG, Shih TY, Tseng WC. 2004. Characterization of the trehalosyl dextrin-forming enzyme from the thermophilic archaeon Sulfolobus solfataricus ATCC 35092. Extremophiles 8: 335-343.

11. Fang TY, Tseng WC, Guo MS, Shih TY, Hung XG. 2006. Expression, purification, and characterization of the maltooligosyltrehalose trehalohydrolase from the thermophilic archaeon Sulfolobus solfataricus ATCC 35092. J. Agric. Food Chem. 54: 7105-7112.

12. Nakada T, Ikegami S, Chaen H, Kubota M, Fukuda S, Sugimoto T, et al. 1996. Purification and characterization of thermostable maltooligosyl trehalose trehalohydrolase from the thermoacidophilic archaebacterium Sulfolobus acidocaldarius. Biosci. Biotechnol. Biochem. 60: 267-270.

13. Siebers B, Tjaden B, Michalke K, Dorr C, Ahmed H, Zaparty M, et al. 2004. Reconstruction of the central carbohydrate metabolism of Thermoproteus tenax by use of genomic and biochemical data. J. Bacteriol. 186: 2179-2194.

14. Qu Q, Lee SJ, Boos W. 2004. TreT, a novel trehalose glycosyltransferring synthase of the hyperthermophilic archaeon Thermococcus litoralis. J. Biol. Chem. 279: 47890-47897.

15. Xavier KB, Martins LO, Peist R, Kossmann M, Boos W, Santos H. 1996. High-affinity maltose/trehalose transport system in the hyperthermophilic archaeon Thermococcus litoralis. J. Bacteriol. 178: 4773-4777.

16. Moon JH, Lee W, Park J, Choi KH, Cha J. 2016. Characterization of a trehalose-degrading enzyme from the hyperthermophilic archaeon Sulfolobus acidocaldarius. J. Biosci. Bioeng. 122: 47-51.

17. Sakaguchi M, Shimodaira S, Ishida SN, Amemiya M, Honda S, Sugahara Y, et al. 2015. Identification of GH15 family thermophilic archaeal trehalases that function within a narrow acidic-pH range. Appl. Environ. Microbiol. 81: 4920-4931.

18. Carroll JD, Pastuszak I, Edavana VK, Pan YT, Elbein AD. 2007. A novel trehalase from Mycobacterium smegmatis purification, properties, requirements. FEBS J. 274: 1701-1714.

19. Choi KH, Hwang S, Cha J. 2013. Identification and characterization of MalA in the maltose/maltodextrin operon of Sulfolobus acidocaldarius DSM639. J. Bacteriol. 195: 1789-1799.

20. Ryu SI, Park CS, Cha J, Woo EJ, Lee SB. 2005. A novel trehalose-synthesizing glycosyltransferase from Pyrococcus horikoshii: molecular cloning and characterization. Biochem. Biophys. Res. Commun. 329: 429-436. 